\title{
Mental Health State of Children with Disabilities and Principles of Rehabilitation
}

\author{
Irina Evgenyevna Kupriyanova, Bairma Antonovna Dashiyeva \\ and Irina Sergeevna Karaush
}

Preventive Psychiatry Department, Mental Health Research Institute, Aleutskaya Street, Tomsk, Russia

Correspondence should be addressed to: Irina Evgenyevna Kupriyanova; niipzso@gmail.com

Received 9 September 2013; Accepted 29 October 2013; Published 25 January 2014

Academic Editor: Małgorzata E.Domagalska

Copyright (C) 2014 Irina Evgenyevna Kupriyanova, Bairma Antonovna Dashiyeva and Irina Sergeevna Karaush. Distributed under Creative Commons CC-BY 3.0

\begin{abstract}
The problem of the increase in the number of disabled children is socially significant. During three years (2008-2011), we have carried out a study on the mental health of children of correctional schools of Tomsk city and of Ulan-Ude city.

The purpose is to investigate the mental health state of children with disabilities and define the principles of rehabilitation. The research included 298 schoolchildren, aged 10-18 years, with basic diagnosis cerebral palsy, hearing disorders, mental retardation of mild degree and 154 parents. Clinical and psychological methods were used.
\end{abstract}

Results: the structure of mental disorders was: speech disorders - 60\%, specific developmental disorders - 34\%, mental retardation - 41\% and hyperkinetic disorders - 5\%. Combined pathology is found in a half of pupils (52\%). With the help of the method of principal component analysis, the influence of the clinical, psychological, biological, social factors on the formation of psychopathological disorders in children was analyzed. The principles of rehabilitation of this category of children were formulated. There the level of anxiety and quality of life of teachers working with children with disabilities were describing. A variety of care programs for children, their parents and teachers of specialized schools was proposed and discussed.

The efficacy have based on the dynamics of mental state, psychological characteristics, social parameters (representing the functional diagnosis) and solutions of psychosocial problems with their parents and teachers.

Keywords: Children with disabilities (cerebral palsy, hearing disorders mental retardation), family factors, Alcohol abuse of parents, level of anxiety, the quality of life of teachers.

\section{Introduction}

The problem of the increase in the number of disabled children is socially significant. According to the prognosis in the last decade, the number of families with disabled children will be increased as much as 2 times and will constitute 1,2-1,5 Millions. Social-economic adaptation of such families is complicated because a part

Cite this Article as: Irina Evgenyevna Kupriyanova, Bairma Antonovna Dashiyeva and Irina Sergeevna Karaush (2014), "Mental Health State of Children with Disabilities and Principles of Rehabilitation," Pediatrics Research International Journal, Vol. 2014 (2014), Article ID 149505, DOI: 
of parents has been forced to leave the job. Special significance is acquired by questions of psychopreventive work, specialized psychiatric, psychotherapeutic and medico-psychological help for children of this category and for the family of the disabled child (Andrienko O.Yu., 2008; Potapov A.I., Rakitsky at all. 2008; Knoche L.L, Edwards C.P. at all., 2012; Sierau, S. at all., 2012).

Basic causes of the increase in the number of disabled children are: increase in the number of risk factors of developmental disturbances (heredity, pathology of pregnancy and birth, adverse ecological environment, professional harms, alcoholism etc.) and improvement of systems of perinatal diagnosis and rehabilitation. All this promotes the increase in the number of children with combined defects of development. Growth of combined pathology increases the risk in the onset of mental symptoms, problems at school and substance abuse. Brunnberg, E., Boström M.L. (2008), Barker D.H., Quittner A.L. at all., (2009) mentioned that regular difficulties of adaptation in children with combined pathology and pathomorphosis of clinic of mental disturbances should be an object for making serious preventive activities. In earlier studies, the basic medication of the disease and pedagogical correction of violations had the primary importance in the rehabilitation of children with disabilities. Insufficiently investigated secondary defects related to disorders of psychological development, the relationship of the individual to own violations and features of the social environment (teachers, parents) affecting the functioning of the child and the efficiency of rehabilitation.

In 2001, the WHO has developed ICF, considering the disease to be a component of health including the assessment of the functional state of the person, personal factors and environmental factors.

In the last investigations, the principles of prevention of secondary disturbances in children with disabilities, principle of early cure by a specialized team (Fordham, L., Gibson, F., Bowes, J. 2012), principle of inclusion of family in rehabilitation (Knoche L.L, Edwards C.P. at all., 2012) are discussed. GinieriCoccossis M., Rotsika V., Skevington S. at all., (2012), in a research study, discuss the early intervention and treatment of children with developmental disturbances that result in increase of likelihood of their occupation in further life and in more stable interpersonal relations. In addition, attention is paid to principle of support for persons coaching children with special needs as well as factors influencing the amount of help necessary for such children (Fournier C.J., Davis, at all, 2010; BourkeTaylor H., Howie M. at all., 2011; Braich, P.S., Lal V., at all 2012). Such researchers as Lesovaya E. (2012), Popov Yu.V., Kmit' K.V. (2012) discuss the phenomenon of «emotional burnout» of parents or «parental fatigue» in the domain of childparent relations, especially in the situation when the child suffers from disabling disease which has also been studied.

Relevance of this problem has allowed defining the aim of the investigation - to investigate the mental health state of children with disabilities and define principles of rehabilitation.

During three years (2008-2011), we have carried out studies of mental health of children of correctional schools of kinds I, II, VIII (№ 15, 45) of Tomsk city and the school of social adaptation of disabled children № 60 of Ulan-Ude city of the Republic of Buryatiya. The study was conducted with the assistance of the medical, social, and educational departments for a comprehensive rehabilitation.

Children's parents signed informed consent of testing and treatment.

\section{Materials}

The investigation has been entered by 298 schoolchildren of grades $4-11$, aged 10-18 years, 192 boys $(64,4 \%)$ and 106 girls $(35,6 \%)$. These schoolchildren are as follows: 
- 92 children from school № 60 of social adaptation of disabled children (UlanUde city of the Republic of Buryatiya, with basic diagnosis cerebral palsy (CP),

- 105 children from Tomsk Regional boarding-school of kind I-II for children with disabilities, having various hearing disorders (sensorineural hearing loss or sensorineural deafness),

- 101 children from school of kind VIII of Tomsk city with diagnosis mild mental retardation.

The inclusion criteria: schoolchildren with disabilities, age - 10-18 years

The exclusion criteria: moderate and severe mental retardation, acute and severe somatic disorders.

154 parents of children with disabilities (68 fathers and 86 mothers) entered the research. Mean age of fathers at the moment of examination has constituted 41, $7 \pm 4,96$ years, mean age of mothers -40 , $1 \pm 5,4$ years. Families with two children are found most frequently - 62, $1 \%$, families with one child constitute $30,1 \%$. Families with many children have constituted 11 (3, $7 \%$ of total number of families); within this category, three families had more than three children. This reflects the demographic situation in the country as a whole and is the consequence of the presence of a child with defect that affects the reproductive potential of the family.

Basic part of children - 186 persons (62, $4 \%$ ) is brought up in families with two parents. As a whole, $37,6 \%$ of children are brought up in families with disturbed structure (step-parent, family with one parent, upbringing by a guardian), that may be a condition negatively affecting the development of the child. In a family with one parent, there are 81 children $(27,2 \%)$, basically brought up by mothers. Most frequently, the cause of family with one child is divorce of parents because of conflicts, father's alcohol abuse, presence of a disabled child, more seldom - death of one of the parents. Twenty children $(6,7 \%)$ are brought up by guardians (as a rule these are relatives), in association with death of parents or annulment. Families of children with disabilities have basically low (51, 1\%) and middle material level (43\%), that affects their everyday functioning and possibilities of optimal rehabilitation of children.

Analysis of the level of education of parents has revealed predominance of secondary special/technical education $(51,3 \%)$ and secondary education (26\%). As a whole, mothers of children of investigated group have higher educational level than fathers. Mothers are often forced to work at lower professional level or to be housewives because of the need to offer care for the disabled child. As a whole, worker's specialties prevail $(42,3 \%)$, the second place is occupied by employees $(25,3 \%)$, the third place is occupied by undertakers (4, 5\%). Group of non-working parents consists of homemakers $(15,6 \%)$ and the unemployed $\quad(13, \quad 3 \%)$ Basically, unemployed persons are fathers $(22,1 \%$ of them), that partially may be explained by their living in rural localities where it is more difficult to find a job; also of significance is the major frequency of alcoholization of the fathers that prevents their stable employment.

\section{Methods}

Research consisted of three stages: screening; clinical and psychological investigation of children, parents and teachers; and rehabilitative. At the stage when screening parents and teachers was proposed to fill in specially developed questionnaires, case stories of children were taken into account. Questioning of form-masters, psychologist, and social teacher allowed revealing individual problems of pupils, being acquainted with traits of studied contingent and defining a kit of psychological methods. Clinical stage included talks with the child, observation of his behavior in various situations (at school, in labor activity, games, during communication with parents, sessions of psychotherapy). We investigated somatic and neurological status of children, and results of paraclinical methods of investigation. Clinical method was added by 
psychological examination, used methods were as follows: CMAS (The Children's Form of Manifest Anxiety Scale), BussDurkey Inventory, projective methods (drawing tests "House-Tree-Man" and drawing of family, Luscher Test).

Statistic method included statistical processing of obtained data with method of multi-dimensional statistic (principal component analysis). Calculation of factors (principal components) for a set of variables, and correlations between the integrated indicators reveal the relationship between the sets. In our study, search integrated indicators included an analysis of 89 clinical, psychological, biological and social characteristics (90 objects). We analyzed clinical and psychological characteristics - presence of mental disorders, combination of pathology, level of anxiety, pathology of upbringing; biological factors - data about perinatal and early periods of development, presence of traumata, infectious diseases, chronic somatic diseases, available family history, and data about health of parents; social-demographic characteristics of the family - place of living, composition, material level, level of education and professional occupation of parents.

During rehabilitative stage we have accomplished programs of help for children with disabilities (psychocorrective, psychotherapeutic,

psychopharmacological), parents and teachers (prevention and correction of emotional burnout syndrome).

\section{Results}

In structure of mental disorders the first positions are occupied by speech disorders - 60\%, specific developmental disorders $34 \%$, mental retardation - $41 \%$ and hyperkinetic disorders - 5\%. Combined pathology is found in a half of pupils (52\%). Pathology of musculoskeletal apparatus has been noticed in 82, 5\%, neurological disorders - 93, 3\%

In $52 \%$ of children, we observed some signs of psycho-organic syndrome - such as apathy, slowing of every activity, weakness of motives, and inertness. In some children, inertness and slowing of mental activity coexists with motional disinhibition, difficulties of concentration of attention. They have typically heightened distractibility, especially toward verbal irritator. Heightened motional activity is one of the phases of fatigue that is replaced by apathy, drowsiness. These peculiarities of asthenia in children differ from asthenia in adults.

Characterizing the level of intellectual development of investigated group, we should say that portion of children with mental retardation has constituted $74,8 \%$ (mental retardation 40, 9\%, impaired mental function 33, 9\%), portion of children with normal level of intelligence $25,2 \%$, within it 67 persons with cerebral palsy $(72,8 \%$ of group) and 8 persons with hearing disorder $(7,6 \%$ of group).

We observed frequently disproportional variant of development of the personality when intellectually sufficient development is combined with absence of independence and self-confidence, heightened suggestibility (in other words underdevelopment of emotional-volitional sphere). As a result, the child forms dependency set, inability and unwillingness to independent practical activity. So, for example, a child with cerebral palsy and able hand activity does not master skills of self-service; children with hearing disorders often refer to their defect to avoid intellectual activity (they feel simply saying "I don't hear" or "I don't understand" than to think about the task). These children need not only therapeutic and social help but also psychological correction; they need assistance in adaptation to conditions of social environment (Dashiyeva, B., Kupriyanova I E, Bayartuyeva SS. 2011, Karaush, I.S, Kupriyanova, I.E. $2 \quad 0 \quad 1 \quad 1$ ).

We have noted for children with disabilities and mental disorders the features of emotional and personal immaturity, frequent changes of mood, tearfulness, a tendency to apathy, difficulty in verbalizing their emotions, states, moods ("I never feel sad"), asthenia, the prevalence of gaming 
motives over education, the desire for pleasure, the limited range of interests, lack of organization activities, and unbalanced behavior were typical.

For children with cerebral palsy hyperexcitability, fears (heights, closed doors, darkness, new people), increased sensitivity to common environmental stimuli, and a tendency to mood swings were characterized. Children with hearing disorders motor awkwardness, impaired fine motor skills, fatigue, more severe speech impairment were characterized. Mental status of children with mild mental retardation was characterized by a severe intellectual impairment, manifested in various spheres of activity and behavior, mainly in the educational activity, impulsivity, and negativism.

During available intellectual, sensory, speech disturbances, anxiety is not always revealed with the help of verbal tests. So, using the scale CMAS only in 16, 5\% have shown high level of anxiety. According to Luscher Test, almost $50 \%$ of children are in state of stress or disadaptation, and according to drawing tests, 93, 5\% have signs of heightened anxiety.

We have taken into account alcohol problems at parents, (Figure 1). Alcohol abuse has been revealed in 29 persons (17, $6 \%)$. To major extent fathers abused alcohol- 21 persons (28\% of number of fathers), than mothers - 8 persons $(8,8 \%)$. In research studies by Nelson S., Kolls J.K. (2002), Solonsky A.V. (2008), Maximenko, A.V. (2010) showed that alcohol use by one or both parents is an adverse one both among biological risk factors for the child and among social ones. This manifests itself in effects of upbringing (hypo-care, conflicts in the family, contradictory upbringing), that adversely affects the development and rehabilitation of children with disabilities. Maternal alcohol abuse is the most tragic for development and prognosis of the child. Such mothers were characterized by denial of evidence of drinking, propensity to seek empathy, strive to justify themselves by formed situation and "hard life circumstances" during evidently insufficient attention paid to child and absence of care to him/her.

Group 1 - parents of children with cerebral palsy, group 2 - parents of children with hearing disorders, group 3 - parents of children with mental retardation.

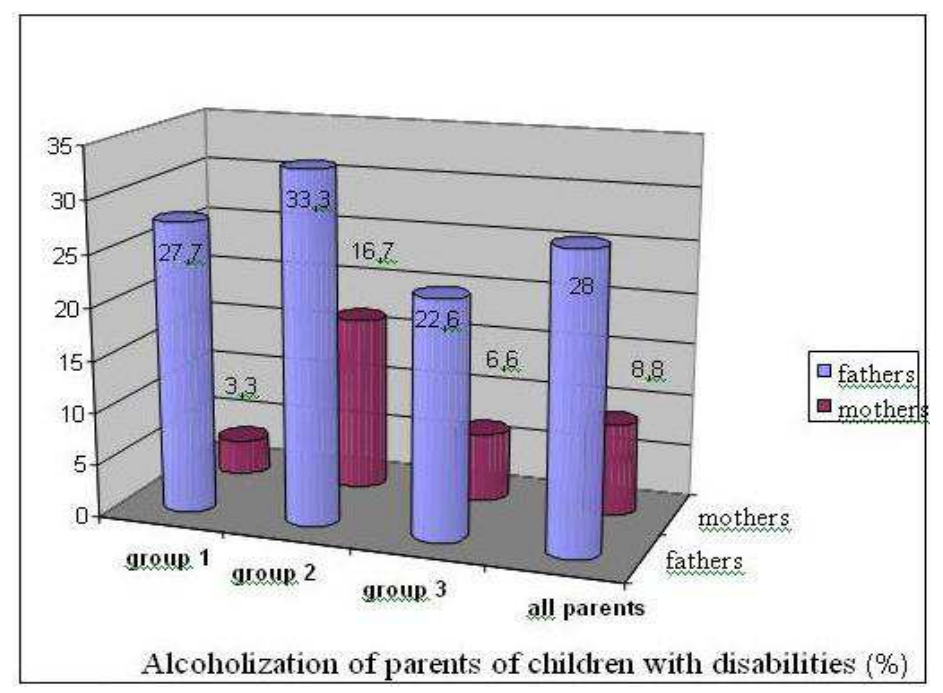

In families with alcohol as everyday life habit, we observed the disappearance of factors necessary for successful functioning of the family, decrease of volitional qualities in the parents, absence of understanding their children and their elementary needs. 
This results in high neuro-mental tension both in family as a whole and in the child in particular. Parental alcoholism of parents conceives social problems in their children: they have heightened risk of attention deficit syndrome and behavioral disorders, offenses; they develop difficulties in communication with peers - significant part of them becomes outcast and an object of ridicule (Kuperman S., Schlosser S. at all., 1999). Moreover, children of drinking parents with great likelihood will become alcohol abusers (Russell M., Cooper M.L., Frone M.R. 1990). Psychological state of children of families where parents have alcohol problems complicates available physical defect.

In order to identify the contribution of clinical, psychological, biological and social characteristics and factors in the origin and formation of mental disorders, we used a method of multivariate statistics - principal component analysis. Calculation of factors (principal components) for a set of variables, and correlations between the integrated indicators reveal the relationship between the sets. In our study, search integrated indicators included an analysis of 89 clinical, psychological, biological and social characteristics (90 objects). Studying case story, we took into account data about perinatal and early periods of development, presence of traumata, infectious diseases, chronic somatic diseases, available family history, and data about health of parents. We analyzed social-demographic characteristics of the family - place of living, composition, material level, level of education and professional occupation of parents, clinical and psychological characteristics - presence of mental disorders, combination of pathology, level of anxiety, and pathology of upbringing.

The first principal component explains $16,9 \%$ of total variability and is represented by a totality of 7 signs: «alcoholization of the father», «composition of the family», «low income», «pathology of upbringing», «place of living (city, village)», «alcoholization of the mother», and «death of parents». Interrelationship of indices of the first principal component reflects characteristics of functioning of the family, and interaction between parents and children. This integral indicator was named "the family». An example of combined impact of adverse signs of this integral index is shown in the clinical case 1.

\section{Clinical Case 1}

0., 17 years old. Diagnosis: sensoneural hearing loss of stage II-III, mental retardation of mild degree, speech disorder F 80.88. She was born in the countryside, parents systematically abused alcohol. During pregnancy her mother smoke and did not stop intake of alcohol. She is a twin child, her brother also has diagnosis of mental retardation. Parents divorced when the girl was 6 years old. Material level of the family was always very low. Early development - with retardation, hearing disorder was revealed after 3 years, parents neglected the development of the child. She did not visit a kindergarten. She studied at boarding school for children with hearing disorders in Tomsk. She learned skills of self-service at school. She studied according to the program of kind VIII and has coped very weakly. Her mother continued to abuse alcohol; from time to time she did not work, and died when 0 . was 14 years old. At the moment, the girl got brought up by a guardian (distant relative). The father is deprived from parent's rights " my family is a cat Musia girlfriend Luda and Kate and the aunt Anna». Since 15 years she started smoking, and episodically in company of peers she uses alcohol drinks. During last two months the girl lives in the family of a classmate whom she is going to marry.

The second principal component $12 \%$ of the total variability) is represented by three variables: the presence of mental disorder, «phobia» and "anxiety». The persons with the presence of phobias in history and high level of anxiety to date were highlighted. This integrated parameter was named «psychopathological disposition». An example of similar ratio may be confirmed by clinical case 2 . 


\section{Clinical Case 2}

R., 13 years old, cerebral palsy, hyperkinetic form, delay of mental development F 83. R. considers his abilities as low; does not believe in his abilities; has no friend among classmates. This boy has low level of learning motivation, predominance of situative interest during the lesson and study because of necessity. During classes, he refuses to do new tasks explaining that he "will not be a success". Failures in study and inability to communicate with peers have formed an aggressive-defensive type of behavior («nobody loves me, but I'm strong »). According to the words of his parents, the boy refused to visit school, complained about ill health during classes feeling satisfactory under home conditions. In family history, the boy had multiple fears (darkness, being alone, dogs, spiders, height). During testing of anxiousness on Spielberger-Khanin, middle level of situative anxiousness and high level of personality one have been revealed. During complex study we have revealed instable attention, with difficulty switched from one kind of activity to another, heightened fatigue, low level of productivity of memory. He experienced great difficulties during learning to write and read, understood badly and could not perform the instructions of the teacher, stack on separate details, and coped with difficulty with logic tasks.

The third principal component - integral index «Spectrum of developmental disturbances» $(7,1 \%$ of total variability), reflects basic components of disturbed development and includes three compounds: «neurological pathology», «musculoskeletal disturbances», and «speech disorders». This parameter has unified children with present musculoskeletal disturbances, speech and neurological disorders.

The forth principal component - integral index «Obstetric history» $(6,8 \%$ of total variability) includes three indices: «pathology of the first half of pregnancy», "pathology of the second half of pregnancy», and «pathology of birth». We most often notice toxicosis, threatened abortion, prolonged stress, infectious diseases during pregnancy, prematurity of various degrees, birth by a Caesarean section, quick or accelerated labor, labor stimulation, extrusion of the fetus, forceps delivery, asphyxia and umbilical cord entanglement. An example of the impact of these factors was presented as clinical case 3.

\section{Clinical Case 3}

M., 12 years old, was born from the second pregnancy (the first was terminated by medical abortion at early term). Pregnancy was with threatened abortion, chronic intrauterine hypoxia of the fetus. The mother was diagnosed cytomegalovirus infection, virus of simply herpes. Delivery was at term 30 weeks; weight $1500 \mathrm{~g}$; rating according to scale of Apgar $3 / 5$ scores, phenomena of perinatal encephalopathy. From discharge summary of Newborns' Pathology Unit : «perinatal lesion of the central nervous system of infectious-ischemic-traumatic genesis, prematurity of degree I, pulmonary atelectasis, intracranial hemorrhage, convulsions, two-sided pyramid deficiency». Up to two years was regularly observed by pediatrician and child neurologist with diagnosis «encephalopathy», was characterized by heightened excitability, tearfulness. In 2 years, lowering of hearing has been revealed, and was diagnosed with sensorineural hearing loss of degree II (right) - III (left). At the moment his mental status is characterized by disturbances of activity and attention, safe intelligence, hypoplasia of verbal means against the background of sensorineural hearing loss. Family with two parents, parents have high education, harmonious upbringing. Younger sister (4 years old) is without peculiarities in development.

The fifth principal component $(6,6 \%$ of total dispersion) «Profession of the mother» is represented by single index «professional occupation of the mother», having distinguished children whose mothers are occupied by working specialties. Within this category are mothers who have high or secondary 
professional education but urged to lower level of their professional claims, much because of the presence of a disabled child. To major extent, this concerns mothers of children with cerebral palsy and hearing disorder. Others originally do not have special professional education.

The sixth principal component $(5,3 \%$ of total variability) «School disadaptation, disturbance of behavior», is represented by three indices, reflecting adaptation to learning activity: «progress at school», «adaptation to school», and «behavior». We distinguished children with disturbance of adaptation to school, low academic progress and presence of behavioral disturbances both within school and family. Disturbances of behavior manifested themselves as abstaining from classes, leaving home, smoking, alcohol use, psychological and physical violence above other schoolchildren (name calling, seizure of personal belongings, making to perform certain actions). This group also included children with low sociometric status in class - «social outcast».

The next clinical case presented an example illustrating disturbance of adaptation to school and disturbance of behavior.

\section{Clinical Case 4}

A., 14 years old, diagnosis cerebral palsy. Till class 6 , she was taught under conditions of home education. She had good progress, waited with joy for teachers, and visited actively the lessons of adaptation and extra lesson activities. Concerning the development of personality, we noticed heightened suggestibility, insecurity, immaturity of emotional-volitional and motivation-need domain. These traits began to manifest brightly with transition of the girl into the class of adaptation (this is one of the forms of training which schoolchildren may choose depending on the state of health). Broadening of the cycle of communication at school and without it reflected at subjective attitude toward her defect. Psychological state was characterized by constant inner conflict, her wishes and intentions often diverged with deeds. She started to pay heightened attention to her appearance («I want to become an actress and star in a movie»). Without taking account for the material well-being of the family, she demanded beautiful things, colored hair almost every week, she wanted to look like others but not like herself. In such a way, she protested against her illness, defect of appearance, refused to accept it. In class 9, she suggested to herself that her name is not happy. During passport preparation, she has changed her name from Anya to Sofia, explaining that she did not want to be "Anna on the neck". We noticed heightened timidity, shyness, absence of initiative, low level of motivation with heightened selfesteem. She was friendly to her classmates but with trust; she did not have close friends. In spite of normal cognitive processes progress with transition into class of adaptation began to fall. Change of learning stereotype, adolescence and inherence in its dysmorphophobic reaction against the background of available defect and traits of personality have negatively reflected on the progress at school and behavior of the adolescent.

Thus, step by step analysis of clinical and psychological, biological and social indicators yielded integral indicators, reflecting the characteristics of family functioning, biological disadvantage, especially social interaction of the child within the family and the school community. These indicators are important for establishing a functional diagnosis, the construction of individual rehabilitation program and determining the prognosis (Table 1). 
Table 1: The Structure of Rehabilitation for Children with Disabilities

\begin{tabular}{|l|l|}
\hline Components & \multicolumn{1}{|c|}{ Focus } \\
\hline Psychopharmacological correction & $\begin{array}{l}\text { Treatment of residual lesions of the central } \\
\text { nervous system } \\
\text { Pharmacocorrection of emotional state }\end{array}$ \\
\hline Psychotherapy & $\begin{array}{l}\text { Optimization of the emotional state } \\
\text { Formation of constructive self-concept } \\
\text { Support activities and initiatives }\end{array}$ \\
\hline Psychocorrection & $\begin{array}{l}\text { Correction of dysfunctional attitudes } \\
\text { Correction of inefficient activities and } \\
\text { communication style }\end{array}$ \\
\hline
\end{tabular}

When counseling parents of children with disabilities we identified the following characteristics (Table 2). These features are targeted by psycho- and psychotherapeutic work. Working with the family increases the effectiveness of the rehabilitation of children.

Table 2: Typical Problems of the Parents of Children with Disabilities and the Directions of their Correction

\begin{tabular}{|c|c|c|}
\hline & The problem & Ways of the decision \\
\hline 1 & Passive attitude to a child's illness & $\begin{array}{l}\text { Focus on the successes of the family; Information about } \\
\text { parents with an active position }\end{array}$ \\
\hline 2 & Depressive settings and status & Treatment of depression \\
\hline 3 & «Rent» attitude to the child's illness & $\begin{array}{l}\text { The detection of the "fictitious purposes" and replacing } \\
\text { them with "real" objectives }\end{array}$ \\
\hline 4 & $\begin{array}{l}\text { Ignoring the disease as a } \\
\text { manifestation of the defensive } \\
\text { behavior }\end{array}$ & $\begin{array}{l}\text { To dispel the illusions of the «normality» of the child; } \\
\text { The belief in the need for care toward the development of } \\
\text { the child }\end{array}$ \\
\hline 5 & «Ashamed» behavior & $\begin{array}{l}\text { Analysis of the process of stigmatization; } \\
\text { «the correction of the environment» }\end{array}$ \\
\hline 6 & $\begin{array}{l}\text { Overprotection, "cultivation" of } \\
\text { secondary defects in child } \\
\text { development, }\end{array}$ & $\begin{array}{l}\text { Search for the causes of overprotection; } \\
\text { The construction of other models of behavior }\end{array}$ \\
\hline 7 & $\begin{array}{l}\text { Syndrome of "parental fatigue" } \\
\text { (emotional burnout parents) }\end{array}$ & $\begin{array}{l}\text { Creating a positive attitude towards themselves and the } \\
\text { acceptance of the situation as an existential problem; } \\
\text { Strengthening of the internal resources of a married } \\
\text { couple }\end{array}$ \\
\hline 8 & $\begin{array}{l}\text { The perception of a child's illness as } \\
\text { a "punishment", guilt }\end{array}$ & $\begin{array}{l}\text { Search irrational prejudices; } \\
\text { Analysis of the possible child's schemes to manipulate } \\
\text { parents; } \\
\text { Development of productive patterns of interpersonal } \\
\text { interaction in the family }\end{array}$ \\
\hline 9 & Hypochondriacal tendencies & $\begin{array}{l}\text { The correction of the "self-image" and «the image of the } \\
\text { child». } \\
\text { The use of body-oriented techniques }\end{array}$ \\
\hline 10 & The parent (s) own problems & $\begin{array}{l}\text { Individual and family psychotherapy; } \\
\text { The identification of the relationship between the } \\
\text { intensity of the problems of the spouses and the illness of } \\
\text { the child }\end{array}$ \\
\hline
\end{tabular}


It should be noted that parents with depressive settings and status syndrome of "parental fatigue" (emotional burnout parents) are more likely to go to medical therapy rather than to undergo psychological adjustment. Problems such as «rent» attitude to the child's illness, and «ashamed» behavior require more significant changes, such as the formation of tolerance in society. "Overprotection ", "cultivation" of secondary defects in child development, hypochondriacal tendencies, and the parent (s) own problems require long-term psychological adjustment.

With problems like «ignoring the disease as a manifestation of the defensive behavior», and «passive attitude to a child's illness», parents refused to help in most cases. The challenges of working with parents are presented in table 3 .

Table 3: Rehabilitation Programs for Family Members and the Teaching Staff

\begin{tabular}{|c|c|}
\hline The programs & The tasks \\
\hline Complex support of the family & $\begin{array}{c}\text { Prevention of emotional exhaustion, social and } \\
\text { personal resources of parents } \\
\text { Psychological assistance to family members }\end{array}$ \\
\hline $\begin{array}{c}\text { Comprehensive assistance in the } \\
\text { educational process }\end{array}$ & $\begin{array}{c}\text { Prevention of burnout of teachers } \\
\text { Psychological activity of the teacher in trouble }\end{array}$ \\
\hline
\end{tabular}

There is not only educational process, but also and upbringing one in special schools/ Students spend much of their time in collaboration with teachers and educators. We have undertaken the study of mental health of members of the teaching staff. We studied the level of quality of life (Gundarov I. A., 1995), anxiety (Hamilton scale) and the degree of professional burnout (K. Maslach questionnaire). In assessing the quality of life, the lowest level of satisfaction includes psychological criteria (peace of mind, relaxation, entertainment, socializing with friends) and physical ones (health, economic status). Those characteristics are shown in Figure 2.

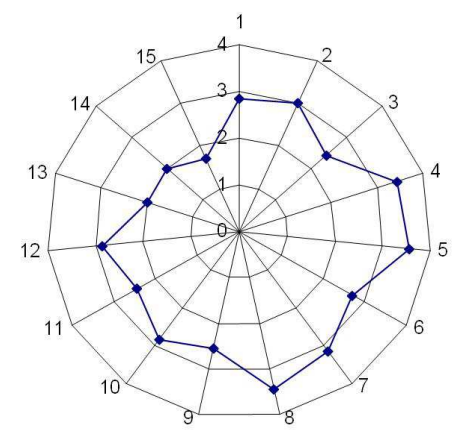

The quality of life of teachers of correctional schools

Criteria: 1 - position in society, 2 - work 3 peace of mind 4 - family of 5 - children 6 health, 7 - the conditions in the community, 8 - housing, 9 - material wealth, 10 - food, 11 - sexual life, 12 - spiritual needs, 13 connect with your friends, 14 entertainment, 15 - rest.

Revealed that $73.3 \%$ of members of the teaching staff of school formed burnout syndrome, in $26.7 \%$ there are all 3 symptoms of burnout syndrome (emotional exhaustion, depersonalization, and reduction of personal achievement). $26 \%$ of the teachers noted the high level of anxiety, which manifests itself in psychic and somatic spheres. Thus, in the state of teachers showed signs of emotional stress and exhaustion, requiring timely correction (Tab. 3). 
The efficacy of rehabilitation was determined by 7 parameters: mental status, physical functioning, daily-household, individual psychological characteristics, interaction with family, teachers and peers. The evaluation was carried out following this scheme: $(-)$ - deterioration, $( \pm)$ - no changes, (+) - an improvement.

The improvement of 4 or more parameters was reached in $12 \%$, of $2-3$ parameters - in $69 \%$, of 1 parameter - in $16.3 \%$, and no changes were in $2.7 \%$.

Of these parameters no changes in the physical functioning, small positive changes in mental status were observed.

The highest dynamics was observed in the psycho- social characteristics that in addition to our estimates, was confirmed by the observations of parents and teachers.

\section{Discussion}

One of the main tasks of rehabilitation of children with disabilities is to adapt the child for life in a society with its violations and ensure a decent quality of life. This problem can not be solved only by determining clinical and nosological diagnosis.

Multivariate approach is used in this study as the basis for multi functional diagnosis, which allows you to evaluate the presence of psychiatric symptoms in the context of microsocial conditions that need to be considered when conducting psychotherapy and psychoprophylactic events (Eidemiller .EG., 2005).

The combination of factors that are of pathological or sanogenetic value determines the prognosis and allows you to create an individual program providing psychological, psychotherapeutic and psychopharmacological help to the child with disabilities and to his family. To form a prediction, the criteria of ICD-10 are often insufficient. Focusing on the ISF criterion expands rehabilitation, but this classification is not currently widespread in the Russian Federation Our study of the multi-functional diagnosis included a comprehensive assessment of integrative clinical parameters (mental status and physical functioning), daily-household, individual psychological and social aspects of life (family, interaction with the teachers and peers). We believe that it is necessary in the rehabilitation of children with disabilities to study the child's family, which forms his mental health and is the main executor of rehabilitation. Parents of disabled children themselves are often in need of support; psychological and medical (including mental health) care. Deficiency of research problems related to disability, promotes isolation of such families, and prevents the use of the rehabilitation potential of the family and the formation of its rehabilitation culture. It is therefore extremely important to consider the characteristics of the environment.

The well-being of children with disabilities enrolled in schools depends on the professional competence and personal characteristics teacher, his psychoemotional state and the emotional atmosphere in the team. Therefore, the rehabilitation programs we developed include psychopharmacological and psychotherapeutic correction, work with the family and the integrated support of the pedagogical process.

Rehabilitation programs are tailored to the following principles:

1. Interdepartmental

2. Preventive orientation

3. Comprehensive assessment of health parameters of children with disabilities physical, mental functioning, the account of the social environment.

4. The principle of inclusion of children with disabilities and their families in the rehabilitation process

5. The principle of psychological support of teachers working with children with disabilities

6. Accounting of the specific of ontogenesis children with disabilities 


\section{Conclusion}

The structure of mental disorders in the study group of children presented spectrum disorder F 7, F 8, F 9. The clinical picture is dominated by symptoms of formation of higher mental functions (speech, thought, perception, attention, memory). Most students have combinative disorder. In the psychological state of children, there was a high frequency of symptoms of anxiety, which manifests deteriorating academic performance and behavior change, which further affects the adaptation in society.

Analysis of the socio-demographic characteristics of families of children with disabilities reveals violations of family functioning on the psychological and social levels: disturbance, abnormal types of education, low or medium level of material, low professional employment of mothers due to forced conversion to homework, a high percentage of parents' alcoholism (17.6\%). These changes require active work with the family as the primary medium forming the mental health of the child. Preservation of mental and physical health of teachers is one of the components of the prevention of mental disorders in children with disabilities and improves quality of life for teachers and teacher effectiveness of interaction with students.

Rehabilitation measures are based on the multi-functional diagnosis and developed principles. They included the complex support of the child, his family and comprehensive assistance in the educational process. The efficacy of rehabilitation was estimated by the dynamics of the parameters of the functional diagnosis: improvement of 4 or more parameters achieved in $12 \%, 2-3$ parameters - $69 \% 1$ parameter - $16.3 \%$. Of these parameters, the highest dynamics was observed in the psycho- social characteristics. Rehabilitation of children, whose parents are actively involved in rehabilitation activities, was the most effective. The decrease in anxiety among the teachers, the normalization of the emotional state was of a positive effect on the functioning and communication of children in school.

Features of the study group of children require the development of new approaches to learning, education and organization of life. This should be done taking into account the full range of medical, educational, social, psychological and other issues relating to support for children with disabilities, their training, education, rehabilitation and adaptation to the social environment. Early diagnosis and correction of development can eliminate current problems and prevent the emergence of secondary abnormalities.

Expanding the range of rehabilitation taking into account established principles, with a focus on the mental health of children, providing psychological assistance to parents and teachers had improved the functioning of children with disabilities.

\section{References}

Andrienko, O. Y. (2008). 'Changing Social Roles and Role Relationships in Families with Children with Disabilities,' Thesis for the Account. step. PhD in sociology. Khabarovsk, Russia.

Barker, D. H., Quittner, A. L., Fink, N. E., Eisenberg, L. S., Tobey, E. A. \& Niparko, J. K. (2009). "Predicting Behavior Problems in Deaf and Hearing Children: The Influences of Language, Attention, and Parent-Child Communication", Development and Psychopathology, 21 (2): 373-392.

Bourke-Taylor, H., Howie, L., Law, M. \& Pallant, J. F. (2011). "Self-Reported Mental Health of Mothers with a School-Aged Child with a Disability in Victoria: A mixed Method Study," Journal of Paediatrics and Child Health, 48 (2): 153-159.

Braich, P. S., Lal, V., Hollands, S. \& Almeida, D. R. (2012). "Burden and Depression in the Caregivers of Blind Patients in India," Ophthalmology; 119(2):221-6. 
Brunnberg, E. \& Boström, M. L. (2008). "Self-Rated Mental Health, School Adjustment, and Substance Use in Hard-ofHearing Adolescents," Journal of Deaf Studies and Deaf Education, 13 (3): 324335.

Cooklin, A. R., Giallo, R. \& Rose, N. (2011). "Parental Fatigue and Parenting Practices during Early Childhood: An Australian Community Survey," Blackwell Publishing Ltd, Child: Care, Health and Development, 38:.654-664.

Dashiyeva, B., Kupriyanova, I. E. \& Bayartuyeva, S. S. (2011). 'Clinical and Psychological Characteristics of Adolescents with Child Cerebral Paralysis,' Siberian Gerald of Psychiatry and Addiction Psychiatry, 3 (66): 41-43

Eidemiller, E. G. (2005). 'Child Psychiatry: A Textbook,' St. Petersburg: St. Petersburg, Russia.

Fordham, L., Gibson, F. \& Bowes, J. (2012). "Information and Professional Support: Key Factors in the Provision of Family-Centred Early Childhood Intervention Services," Child: Care, Health and Development, 38 (5):647-53.

Fournier, C. J., Davis, M. J., Patnaik, A., Elliott, T. R., Dyer, J. A., Jasek, E. E. \& Phillips, C. D. (2010) "Modeling Caregivers' Perceptions of Children's Need for Formal Care: Physical Function, Intellectual Disability, and Behavior," Disability and Health Journal, 20103 (3):213-21.

Ginieri-Coccossis, M., Rotsika, V., Skevington, S, Papaevangelou, S., Malliori, M., Tomaras, V. \& Kokkevi, A. (2012). "Quality of Life in Newly Diagnosed Children with Specific Learning Disabilities (SpLD) and Differences from Typically Developing Children: A Study of Child and Parent Reports," Child: Care, Health and Development, Early View, [Online], [Retrieved Februar 22, 2013] 10.1111/j.1365-2214.2012.01369.x

Gundarov, I. A. (1995). 'Rose of the Quality of Life,' Siberian health; 1:15-16.
Hogan, A. Shipley, M., Strazdins, L., Purcell, A. \& Baker, E. (2011). "Communication and Behavioural Disorders among Children with Hearing Loss Increases Risk of Mental Health Disorders," Australian and New Zealand Journal of Public Health, 35 (4): 377-383

Ivanov, E. S. (2002). 'Psycho-Diagnostics and Correction of Children with Disabilities and Development,' Comp. And Overall Revision VM Astapova, Y. Mikadze. St. Petersburg.: Peter, Russia.

Karaush, I. S. \& Kupriyanova, I. E. (2011). 'Medico-Psychological Coaching of Children with Hearing Disorders,' Siberian Gerald of Psychiatry and Addiction Psychiatry, 3 (66): 47-49.

Knoche, L. L., Edwards, C. P., Sheridan, S. M., Kupzyk, K. A., Marvin, C. A., Cline, K. D. \& Clarke, B. L. (2012). “Getting Ready: Results of a Randomized Trial of a RelationshipFocused Intervention on the Parent-Infant Relationship in Rural Early Head Start," Infant Mental Health Journal, 33 (5): 439458.

Kuperman, S., Schlosser, S., Lidral, J. \& Reich, W. (1999). "Relationship of Child Psychopathology to Parental Alcoholism and Antisocial Personality Disorder," Journal of the American Academy of Child \& Adolescent Psychiatry. 38: 686-692.

Kupriyanova, I. E., Semke, V. Ya., Dashieva, B. A. \& Karaush, I. S. (2011). 'Mental Health of Children with Special Educational Needs,' «Tomsk Publishing House Ivan Fedorov», Russia.

Lesovaya, E. (2012). 'Spread Your Wings! Or What is the Emotional Burnout and How to Cope with it,' Teacher's newspaper. Moscow 31.07.; 31.

Maximenko, A. V. (2010). 'Clinical Features of Mental Retardation in Children Due to Parental Alcoholism (Regional, Psychosocial, Rehabilitation Aspects),' Thesis for the Account, step. PhD in medicine. Kemerovo, Russia. 
Nelson, S. \& Kolls, J. K. (2002). "Alcohol, Host Defense and Society," Nature Reviews Immunology. 2: 205.

Popov, Y. V. \& Kmit, K. V. (2012). "Burnout - Is it Nothing but the Result of Professional Relations?," V.M. Bekhterev review of psychiatry and medical psychology, 2: 98-101.

Potapov, A. I., Rakitsky, V. N., Novichkova, N. I. \& Romanova, E. A. (2008). 'Problems of Russian Children's Health,' Health of the Russian Federation, 3: 3-5.

Russell, M., Cooper, M. L. \& Frone, M. R. (1990). "The Influence of Sociodemographic Characteristics on Familial Alcohol Problems: Data from a Community Sample," Alcoholism: Clinical and Experimental Research, 14: 221-226.

Sierau, S., Brand, T. \& Jungmann, T. (2012). "Parental Involvement in Home Visiting: Interpersonal Predictors and Correlates," Infant Mental Health Journal, 33 (5), 489495.

Solonsky, A. V. (2008). 'Morphologic Patterns of the Early Stages of Brain Development in the Conditions of Prenatal Alcohol Abuse: Thesis for the Account,' step. PhD in medicine. Tomsk, Russia. 